economic species, ${ }^{*}$ and species* of importance to sustainable development;

- data on the status and distribution of habitats of conservation concern and sites of high biological diversity within these habitats;

- data on the world's protected areas, the main species and habitats which they contain, and the type and effectiveness of the protection that they afford;

- data on the utilization of wild species, and on the patterns and volume of the international trade in wild species and their derivative products; and

- a conservation bibliography to provide references to support these database themes.

Output from this database provide usable information to support the international programmes of the partner organizations and the wider conservation and development community. Primary users are the multinational and bilateral development agencies, government environmental institutes, and non-governmental conservation organizations, as well as multinational corporations and the industrial sector, journalists and television programme makers, university and research institutes, schools, scientists, and individuals involved in conservation work. Particular attention is given to provide the data support needed for the effective operation of all the major international conservation conventions and programmes, including CITES, the World Heritage Convention, the Man and the Biosphere Programme, Ramsar, the International Timber Trade Organization, the Bern Convention, and others.

* As used here, the term species evidently covers also lower taxa. Ed.
WCMC has a policy of charging users who can afford to pay for its information services at a competitive market rate to support the maintenance of its database, although much of its data capture depends upon the free two-way exchange of information.

Most decisions influencing conservation are taken at the national or local level, and WCMC is committed to the establishment of National Conservation Data Centres in developing countries as a priority for improving the availability of information to support national conservation and development projects.

Through its outreach programme, the Centre is also establishing links with other sectoral or geographicallyrestricted databases that are active in the field of biological diversity, to develop a distributed information network. This programme necessitates the development and active promotion of standard terminologies, classification systems, and data transfer formats, to encourage information exchange between database agencies.

This is an ambitious programme. WCMC has the commitment, the necessary expertise, and, through the partnership it now has, the core funding to do the job. However, it still looks to the wider scientific and conservation community as the source of the data, for mutually beneficial data exchange, and for guidance and support in carrying this programme forward.

RoBIN A. PELLEW, Director
World Conservation Monitoring Centre
1219 c Huntingdon Road
Cambridge CB3 ODL
England
UK.

\title{
Bridging the Gap Between Theory and Practice: A Systematic Programme of Global Education
}

How inspiring it is to read of conferences which present the future for humanity as one of great hope and infinite possibilities, of new relationships among people and with Nature, of a caring and compassionate world, and so many other valuable initiatives! However, at the same time, I read such reports also with a profound sadness. Below, I try to explain why.

The visions of a better world, the light and hope experienced by the participants of conferences are not, for the most part, reaching the great masses of people - the many millions of men and women beyond the conference halls, beyond the newsletters and journals, and beyond the visions and hopes. Certainly there are more and more conferences dedicated to the future of humanity, and there is no question that these are helpful for sharing ideas among visionaries, futurists, and men and women of goodwill; but what about the rest of the people housewives, professional drivers, postmen, local public employees, factory workers - to mention just a few of that great entity comprising 'humanity'? If indeed the challenge to create a better world faces humanity, then surely it is humanity which needs to learn of the hopes, the dreams, and the visions that are apt to be described so eloquently.

The above-mentioned visions are but part of a wider store of riches to which the people at large are entitled. There is a vast wealth at the heart of our planet - an accumulated treasure of wisdom, comprising the perceptions and thoughts of men and women of science and philosophy - a wealth of spiritual and intellectual wisdom. This wisdom is the rightful heritage of all people, and is the basis for the effective use of human consciousness - for the awakening of global ethics and universal common human values. This wisdom, effectively and creatively shared with humanity, can stimulate change in human attitudes and motivate constructive change in human behaviour. Is this not what is needed to create a more humane world?

\section{Duty of Leaders}

Is it not part of the inherent responsibility of thinking people, of people of goodwill and vision, and of leaders of social organizations, to ensure that this wealth is made understandable and accessible to all people everywhere in the world, so that they are informed, awakened, and sensitized to their role in creating a better future?

If the wisdom of visionaries, futurists, and men and women of goodwill, is pictured as a 'cloud' (i.e. the theory of a better future), a large 'gap' exists between this cloud and the consciousness of the many millions of people whose energy and practical cooperation is a prerequisite to the implementation of the theory of an improved future. For the vision to be actualized, the 'gap' must be bridged.

Conferences alone, no matter how frequent and individually impressive, or even if given coverage by television satellites, are not adequate to enhance public awareness, world-wide, of global consciousness and universal values of human responsibility. There is a tendency for the 'good news' - including encouraging visions of the future - to be shared among the 'converted'; but it is 
now essential that the great numbers of people beyond these circles be reached and involved, for it is these people who form the majority of the populations on the planet, and without them the building of a bright future cannot go ahead. In this respect there is a need for a steady, systematic programme of global education - a programme that is ongoing, dynamic, creative, and especially designed to reach the hearts and minds of the many millions of men and women in all regions and communities at the very grassroots of societies everywhere in the world.

The global education programme must be dedicated to translating the values for a better world - into understandable 'kernels'. These need to be concise, attractive, imaginative, and lively - designed not only to capture the interest of people, but also to motivate them to express their reactions in their daily lives and relationships. The phrase 'thinking globally, acting locally' must become much more widely understood and used than it is at present, the need being for the masses everywhere to practice what they hear preached (though of course having heard it!).

\section{The Programme of Global Education}

This must be conveyed through a world-wide communications network - a network linking up the channels of diverse organizations throughout the world - to ensure the simultaneous transmission of information to many thousands of organizations at local, national, regional, and international, levels, using all available means of communications and complemented by use of the media whenever possible.

The framework for this much-needed world-wide communications network is already being created: the New Computerized World Information Service (NCWIS) was launched at an international meeting of nongovernmental organizations in Geneva, Switzerland, in May 1989. The meeting was sponsored by the World Information Clearing Centre (WICC), also situated in Geneva.

The NCWIS is developing a global network of interactive communications combining computer link-ups with telex, telefax - and even postal systems where, at present, no other methods of communications are available. To 'humanize' the items of information (i.e. to make them widely understandable and interesting), visual presentations are used whenever possible. An International Advisory Panel (IAP), comprising scientists, humanists, and men of vision, is being created to provide guidance in elaborating 'humanized' information. The NCWIS provides a vehicle for a steady and systematic, global education programme. It is designed to bridge the gap between the visionary 'cloud' of theory for a better future and the consciousness of the world's people.

\section{World Information Clearing Centre Branches Needed World-wide}

To develop the NCWIS, regional branches of WICC are being established in all parts of the world. The regional WICC branches provide relay points for information exchange among participating organizations, and stimulate the development of improved communications concerning environmental matters everywhere. At the same time the WICC/NCWIS programme is dedicated to promoting goodwill and cooperation among people for building a better world. It is guided by the principles of the United Nations, and is developing cooperation with the specialized agencies of the United Nations inter alia to promote more effective dissemination of information on their activities than is currently available. WICC is linked with the United Nations International Computing Centre (UN ICC), Geneva.

The role of WICC Geneva is to assist nongovernmental organizations (NGOs) of all social and professional profiles to improve their communications' ${ }^{\prime}$ capacities concerning networking, technical equipment, and training matters - towards the widest and most effective dissemination and exchange of information among networks at local, national, regional, and international, levels and particularly to reach the grassroots of societies everywhere in the world. WICC is pleased to have the cooperation of the Hewlett-Packard Company (HP), whose assistance is provided both in Geneva and in all regions and countries where the NCWIS is being developed.

The NCWIS can make a contribution to saving the future of the planet. But its potential can be realized only with the active participation of men and women of goodwill - of scientists, humanists, visionaries, and spiritual and other leaders - together with representative organizations and scientific and educational institutions. Especially desirable are those who realize the need to close the 'gap' between the theory of a better future and the understanding of the role of the people in implementing it: without people's widest involvement, the theories and visions - even the most beautiful, inspiring, and valid ones - remain simply theories and visions.

SALly CURRY, Executive Secretary World Information Clearing Centre 14 Chemin Auguste-Vilbert 1218 Grand-Saconnex Geneva Switzerland.

\section{Multidisciplinary Assessment of Environmental Risks for Human Health: Summer School in Italy}

Once again this year the University of Siena is organizing a 2-weeks' long Summer School on this important theme, subtitled 'Contaminants in the Environment'. It will last from Monday 3 September until Saturday 15 September 1990, and the main topics will be:

- Distribution, levels, and fate.

- Comparative aspects of metabolism and toxicity.

- Detoxication strategies.

- Damage to biological structures.

- Pesticides and risks for human health.

Food, lodging, and travel expenses, will be provided for 15 Italian students; food, lodging, and part of their travel expenses, will be provided for 15 foreign students. A degree in Medicine or Biology is normally required of applicants, but holders of degrees in related fields may also be considered. The official language of the Summer School will be English.

If interested, please forward your application, curriculum vitae, list of publications, letter(s) of recommendation, and a brief abstract regarding one of the School topics (or of your personal research) for possible short presentation during the School, to:

\section{Professor Aristeo RenZONI Dipartimento di Biologia Ambientale Via delle Cerchia 3 53100 Siena, Italy.}

Telephone 0577-298831

Telefax 0577-298860

Telex 572459 UNIVSI I. 